\title{
The MOPITT Version 6 product: algorithm enhancements and validation
}

\author{
M. N. Deeter ${ }^{1}$, S. Martínez-Alonso ${ }^{1}$, D. P. Edwards ${ }^{1}$, L. K. Emmons ${ }^{1}$, J. C. Gille ${ }^{1}$, H. M. Worden ${ }^{1}$, C. Sweeney ${ }^{2}$, \\ J. V. Pittman ${ }^{3}$, B. C. Daube ${ }^{3}$, and S. C. Wofsy ${ }^{3}$ \\ ${ }^{1}$ Atmospheric Chemistry Division, National Center for Atmospheric Research, Boulder, CO, USA \\ ${ }^{2}$ Global Monitoring Division, NOAA/ESRL, Boulder, CO, USA \\ ${ }^{3}$ Department of Earth and Planetary Sciences, Harvard University, Cambridge, MA, USA
}

Correspondence to: M. N. Deeter (mnd@ucar.edu)

Received: 15 May 2014 - Published in Atmos. Meas. Tech. Discuss.: 18 June 2014

Revised: 11 September 2014 - Accepted: 26 September 2014 - Published: 5 November 2014

\begin{abstract}
The Measurements of Pollution in the Troposphere (MOPITT) Version 6 (V6) product for carbon monoxide (CO) incorporates several enhancements which will benefit many users of MOPITT data. V6 algorithm improvements are described in detail, and V6 validation results are presented. First, a geolocation bias related to the orientation of the MOPITT instrument relative to the TERRA platform was characterized and eliminated. Second, the variable a priori for $\mathrm{CO}$ concentrations for V6 is based on simulations performed with the chemical transport model Community Atmosphere Model with Chemistry (CAM-chem) for the years 2000-2009 instead of the model-derived climatology for 1997-2004 used for V5. Third, meteorological fields required for V6 retrieval processing are extracted from the MERRA (Modern-Era Retrospective Analysis For Research And Applications) reanalysis. Finally, a significant latitudedependent retrieval bias in the upper troposphere in Version 5 products has been substantially reduced.
\end{abstract}

\section{Introduction}

Measurements of Pollution in the Troposphere (MOPITT) is an instrument on the NASA Terra platform designed to permit retrievals of tropospheric profiles of carbon monoxide (CO) using both thermal-infrared (TIR) and near-infrared (NIR) observations. Satellite measurements of $\mathrm{CO}$ enable air quality forecasts as well as a variety of studies of pollution sources, transport, and atmospheric chemistry (Shindell et al., 2006). The MOPITT instrument has been operating nearly continuously since 2000 (Drummond et al., 2010). MOPITT retrieval products have improved continuously as the result of accumulated knowledge regarding the instrument, forward modeling methods, and geophysical variables. The history of retrieval algorithm development for the MOPITT mission was recently summarized in Worden et al. (2014).

Version 6 products described in this manuscript build on Version 5 products which were introduced in 2011. The V5 product included the first "multispectral" satellite product for CO to exploit simultaneous TIR and NIR observations (Deeter et al., 2013). MOPITT remains the only satellite instrument with this capability. TIR-only and NIR-only retrieval products are also produced operationally since each of these three products has relative strengths and weaknesses. The TIR/NIR product offers the greatest vertical resolution and particularly the greatest sensitivity to $\mathrm{CO}$ in the lower troposphere. However, this product also exhibits relatively large random retrieval errors and bias drift. Moreover, the main benefits of this product are only evident in daytime MOPITT observations over land. The TIR-only product offers the highest temporal stability and similar performance in variable observing situations (day and night, land and ocean). The NIR-only product is most suited for the analysis of CO total columns but is strictly limited to daytime observations over land. 


\section{V6 algorithm features}

\subsection{Geolocation bias correction}

Geolocation data (i.e., latitude and longitude values) reported in previous (V3, V4, and V5) MOPITT Level 1 and Level 2 products appear to be biased due to a misalignment between the MOPITT reference frame and the Terra platform. As described in a technical report available on the MOPITT website (Deeter, 2012), a method was developed to quantify the angular misalignment from observations of latitudinal and longitudinal biases in daytime overpasses. The estimated along-track viewing angle bias was $0.59^{\circ}$ while the estimated cross-track viewing angle bias was $2.61^{\circ}$. The corresponding uncertainty in these viewing angle corrections was estimated as $0.4^{\circ}$. An experimental Level 1 processor (i.e., the processing software which generates the MOPITT Level 1 radiance product) which explicitly corrects for the viewing angle bias was developed and used to validate the correction method. Comparisons of MOPITT radiances and retrieval products in various geographical regions before and after the geolocation correction indicate that the method essentially eliminates the geolocation bias. The resulting improvement in geolocation is illustrated in Fig. 1, where gridded NIR (Channel 6) clear-sky radiances are shown for all daytime overpasses of Baja California during 2002. The left and right panels present V5 (uncorrected) and V6 (corrected) gridded radiances, respectively. The coastline separating the low-albedo ocean and high-albedo land is clearly positioned more accurately in the V6 data.

\subsection{CO a priori}

Like the V4 and V5 products (Deeter et al., 2010, 2013), the V6 products rely on variable a priori to represent the geographical and seasonal variability of "background" concentrations of $\mathrm{CO}$. Whereas for earlier products $\mathrm{CO}$ a priori concentrations were based on monthly climatologies for the years 1997-2004 (Deeter et al., 2010) and was simulated with the Model for OZone and Related chemical Tracers (MOZART) (Emmons et al., 2010), for V6 the a priori $\mathrm{CO}$ is based on monthly climatologies for the years 20002009 simulated with the Community Atmosphere Model with Chemistry (CAM-chem) model (Lamarque et al., 2012). MOPITT a priori volume mixing ratio (VMR) values vary by month, but do not vary from year to year; this simplifies the interpretation of long-term trends in the data. A potential advantage of the new a priori is that it should represent mean global CO concentrations during the actual MOPITT mission (2000 to present) better than the V5 a priori. Like the previous MOZART-based climatology, the new CAM-chembased climatology is gridded at $1^{\circ}$ (latitude/longitude) horizontal resolution and monthly temporal resolution. Spatial and temporal interpolation are used to generate a priori values at a specific location and day.

\subsection{Meteorological data}

For each CO retrieval, the MOPITT retrieval algorithm requires temperature and water vapor profiles as well as a priori surface temperature values. In previous operational processors, relevant meteorological data were extracted from NCEP (National Center for Environmental Prediction) GDAS (Global Data Assimilation System) forecast products and then interpolated spatially and temporally to each MOPITT observation. For V6 processing, meteorological profiles are interpolated from the NASA MERRA (ModernEra Retrospective Analysis For Research And Applications) reanalysis product (http://gmao.gsfc.nasa.gov/merra/) (Rienecker et al., 2011). Several benefits are anticipated as a result of using MERRA products rather than NCEP. First, generally higher-quality retrieval results are expected due to higher-quality water vapor profiles; unphysical values in NCEP water vapor profiles (Deeter et al., 2013) were previously found to sometimes cause anomalous surface-level CO concentrations over the ocean offshore the state of California. Also, higher-quality retrieval results should be achieved over land due to the use of hourly resolved MERRA surface skin temperatures instead of 6-hourly NCEP surfacelevel air temperatures; skin temperature more closely represents the radiative surface temperature to which MOPITT thermal-channel radiances respond. Higher-quality retrieval results are also expected due to higher horizontal and vertical spatial resolution in the meteorological fields; MERRA is produced at $1 / 2$ by $2 / 3^{\circ}$ (latitude/longitude) horizontal resolution on a 42-level pressure grid, whereas NCEP GDAS products are produced at $1^{\circ}$ horizontal resolution on a 26level pressure grid. Finally, we expect improved long-term stability of MOPITT retrieval products as the result of the use of climate-quality reanalysis instead of output from a meteorological forecasting system. MERRA reanalysis products are typically released 1 month at a time, with a data latency of about 2 to 3 weeks. This leads to data latencies for MOPITT V6 products of 1 to 2 months and prevents their use in near-realtime applications. However, a non-operational V6 processing system for near-realtime applications has been developed exploiting the GEOS-5 forecast products instead of MERRA. Results from this alternative processing system have not been thoroughly evaluated.

\subsection{Radiance bias corrections}

The MOPITT operational processing software exploits a set of radiance-bias correction factors to compensate for relative biases between (1) simulated radiances calculated by the operational radiative transfer model and (2) actual calibrated Level 1 radiances. Without some form of compensation, radiance biases produce biases in the retrieved $\mathrm{CO}$ profiles. Radiance bias correction factors compensate for a variety of potential bias sources including errors in instrumental specifications, forward model errors, spectroscopy errors, 


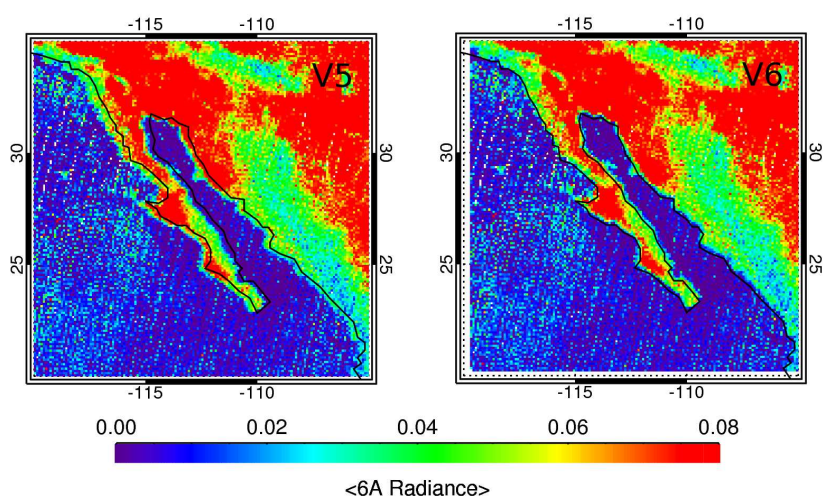

Figure 1. Gridded Channel 6 "Average" (6A) NIR radiances for daytime MOPITT overpasses of Baja California during 2002. NIR radiances are generally larger over land than over ocean because of higher albedo. V5 radiances in the left panel clearly exhibit a lateral shift (or geolocation bias) between the true coastline and the coastline indicated by the radiances. This bias is greatly reduced in the V6 radiances presented in the right panel.

and geophysical errors. They were first introduced to compensate for observed biases in Channel 5 radiances (Deeter et al., 2004), but are useful for compensating for biases in both Channel 5 and 7 (TIR) radiances. No significant radiance bias was observed for the MOPITT Channel 6 (NIR) radiances in Version 5 products; hence, radiance bias correction has so far only been employed for the TIR radiances. Prior to releasing new MOPITT products, final correction factors are determined iteratively, using retrieval validation results for $\mathrm{CO}$ retrieved profiles and total column as indicators of radiance bias. The number of iterations employed in this process is however limited because of the large computational expense.

Validation results for both the V5 TIR-only and TIR/NIR products indicated a substantial bias at $200 \mathrm{hPa}$ (Deeter et al., 2013). Specifically, for the V5 TIR-only product, the observed overall bias at $200 \mathrm{hPa}$ was $7.9 \%$ using the NOAA in situ profiles, mainly representing North America, and $10 \%$ using the HIAPER (High-performance Instrumented Airborne Platform for Environmental Research) Pole-to-Pole Observations (HIPPO) field campaign profiles over the Pacific Ocean (described below). However, analysis of the V5 HIPPO validation results revealed that the bias at $200 \mathrm{hPa}$ was strongly latitude dependent, with biases in the tropics reaching roughly $20-30 \%$ and much smaller biases in midlatitude and polar regions. For V6, the radiance correction factors for radiances $5 \mathrm{~A}, 5 \mathrm{D}$, and $7 \mathrm{D}$ were revised in order to reduce the large retrieval bias at $200 \mathrm{hPa}$ without severely degrading the retrieval biases at other retrieval levels. For V5, radiance correction factors for the TIR radiances $5 \mathrm{~A}, 5 \mathrm{D}$, and 7D were respectively set to $0.99680,0.98570$, and 0.97000 . For V6 processing, radiance correction factors were revised to $0.99685,0.98565$, and 0.90000 . The significant change in the 7D radiance correction factor reflects the primary role of the 7D radiance on retrieved $\mathrm{CO}$ concentrations in the upper troposphere (Deeter et al., 2004).

\section{$3 \quad$ V6 validation results}

Retrieval validation involves statistical comparisons of MOPITT retrieval products (CO VMR profiles and total columns) with in situ measurements. For this purpose, we consider the in situ measurements to be exact and assume that the in situ vertical profiles are representative horizontally over an extended region around the sampling location. A collocation radius of $50 \mathrm{~km}$ was employed for the NOAA profiles and $200 \mathrm{~km}$ for the HIPPO profiles. The larger acceptance radius for the HIPPO profiles is justified by the expectation that $\mathrm{CO}$ vertical and horizontal gradients in the vicinity of the HIPPO profiles should generally be much weaker than for the NOAA aircraft profiles, because of the remoteness of these profiles relative to $\mathrm{CO}$ source regions. This choice has consequences for the effects of random retrieval errors, as described in Sect. 3.2.1. Because of the coarseness of the radiance weighting functions (or "Jacobians") and the underconstrained nature of the retrieval process, retrieval products obtained with optimal estimation-type retrieval algorithms are constrained by a priori information as well as the measurements (Pan et al., 1998; Rodgers, 2000). A priori information is represented by (1) an a priori profile $x_{\mathrm{a}}$ and (2) an a priori covariance matrix, which determines the strength of the a priori constraint. The relationship between the true profile $x_{\text {true }}$, $x_{\mathrm{a}}$, and retrieved profile $x_{\mathrm{rtv}}$ is expressed by the equation

$x_{\mathrm{rtv}}=x_{\mathrm{a}}+\mathbf{A}\left(x_{\text {true }}-x_{\mathrm{a}}\right)$,

where $\mathbf{A}$ is the averaging kernel matrix. The vector quantities $x_{\text {true }}, x_{\mathrm{a}}$, and $x_{\text {rtv }}$ are expressed in terms of the logarithm of the VMR rather than VMR itself (Deeter et al., 2007). A quantifies the sensitivity of the retrieved profile to the true profile and is provided as a diagnostic for each retrieval in all MOPITT products. A depends on the weighting functions, a priori covariance matrix, and instrument error covariance matrix. As an example, retrieved $\mathrm{CO}$ profiles and mean averaging kernels for the V6 TIR-only product are shown in Fig. 2. Retrievals were drawn from observations on 10 April 2010 over an area near Hawaii between 20 and $24^{\circ} \mathrm{N}$, and 160 and $156^{\circ} \mathrm{W}$. For clarity, mean averaging kernels are only shown for alternating levels, starting with the surface. Each plotted averaging kernel corresponds to one row of A. Thus, when $x_{\text {true }}$ is known (from in situ measurements, for example), Eq. 1 provides a formula for calculating simulated retrievals which account for the inclusion of a priori information and the smoothing effect of the averaging kernel matrix (Rodgers, 2000). MOPITT retrieved total column values are compared with simulated total column values as described previously (Deeter et al., 2013). 
Table 1. NOAA validation site locations.

\begin{tabular}{lrrl}
\hline NOAA validation site & Latitude & Longitude & Observational period \\
\hline Poker Flat, Alaska & $65.07^{\circ} \mathrm{N}$ & $147.29^{\circ} \mathrm{W}$ & $17 / 4 / 00-26 / 4 / 13$ \\
East Trout Lake, Saskatchewan & $54.35^{\circ} \mathrm{N}$ & $104.98^{\circ} \mathrm{W}$ & $14 / 8 / 06-21 / 9 / 13$ \\
Dahlen, North Dakota & $47.50^{\circ} \mathrm{N}$ & $99.24^{\circ} \mathrm{W}$ & $14 / 4 / 05-13 / 9 / 13$ \\
Worcester, Massachusetts & $42.95^{\circ} \mathrm{N}$ & $70.63^{\circ} \mathrm{W}$ & $31 / 3 / 05-22 / 8 / 13$ \\
Harvard Forest, Massachusetts & $42.54^{\circ} \mathrm{N}$ & $72.17^{\circ} \mathrm{W}$ & $27 / 2 / 01-18 / 11 / 07$ \\
West Branch, Iowa & $41.72^{\circ} \mathrm{N}$ & $91.35^{\circ} \mathrm{W}$ & $7 / 11 / 04-10 / 12 / 13$ \\
Trinidad Head, California & $41.05^{\circ} \mathrm{N}$ & $124.15^{\circ} \mathrm{W}$ & $2 / 9 / 03-11 / 12 / 13$ \\
Beaver Crossing, Nebraska & $40.80^{\circ} \mathrm{N}$ & $97.18^{\circ} \mathrm{W}$ & $2 / 11 / 04-21 / 6 / 10$ \\
Briggsdale, Colorado & $40.37^{\circ} \mathrm{N}$ & $104.3^{\circ} \mathrm{W}$ & $2 / 5 / 00-30 / 12 / 13$ \\
Homer, Illinois & $40.07^{\circ} \mathrm{N}$ & $87.91^{\circ} \mathrm{W}$ & $15 / 12 / 04-21 / 11 / 12$ \\
Cape May, New Jersey & $38.83^{\circ} \mathrm{N}$ & $74.32^{\circ} \mathrm{W}$ & $17 / 8 / 05-13 / 12 / 13$ \\
Norfolk, Virginia & $36.70^{\circ} \mathrm{N}$ & $75.50^{\circ} \mathrm{W}$ & $8 / 6 / 05-29 / 4 / 07$ \\
Charleston, South Carolina & $32.77^{\circ} \mathrm{N}$ & $79.55^{\circ} \mathrm{W}$ & $16 / 2 / 04-9 / 11 / 11$ \\
Sinton, Texas & $27.73^{\circ} \mathrm{N}$ & $96.86^{\circ} \mathrm{W}$ & $1 / 10 / 03-22 / 6 / 13$ \\
Molokai, Hawaii & $21.23^{\circ} \mathrm{N}$ & $158.95^{\circ} \mathrm{W}$ & $12 / 12 / 00-15 / 4 / 08$ \\
Rarotonga, Cook Islands & $21.25^{\circ} \mathrm{S}$ & $159.83^{\circ} \mathrm{W}$ & $22 / 3 / 01-27 / 6 / 13$ \\
\hline
\end{tabular}
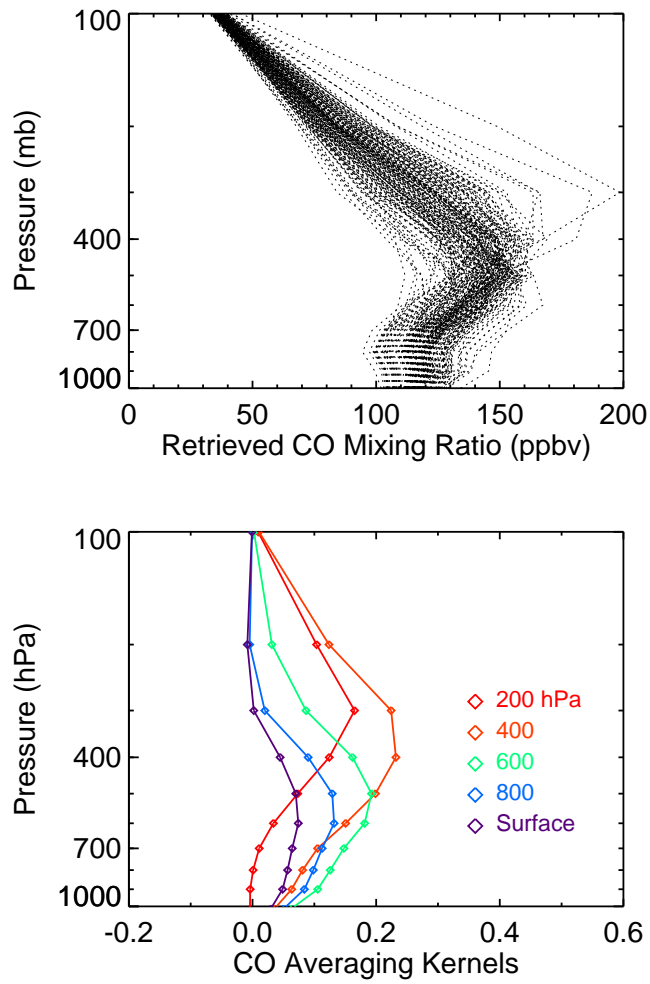

Figure 2. V6 TIR-only retrieved CO profiles (top) and associated mean averaging kernels (bottom) for observations obtained on 10 April 2010 between 20 and $24^{\circ} \mathrm{N}, 160$ and $156^{\circ} \mathrm{W}$.

\subsection{Results based on NOAA aircraft profiles}

In situ measurements of $\mathrm{CO}$ concentrations acquired through NOAA's flask sampling program have served as the foundation for previous MOPITT validation efforts (Emmons et al., 2009; Deeter et al., 2013). Flask samples obtained on aircraft are processed by the Global Monitoring Division of NOAA's Earth System Research Laboratory (ESRL). NOAA stations used for MOPITT validation are primarily located in North America and are listed in Table 1. Aircraft profiles acquired through the end of 2013 were exploited to validate the MOPITT V6 product. Flask samples are typically acquired from near the surface up to about 350-400 hPa. Typical in situ profiles are derived from approximately 12 flask samples. In order to obtain a complete validation profile for comparison with MOPITT retrievals, each in situ profile is extended vertically above the highest in situ measurement using the chemical transport CAM-chem (to be consistent with the new V6 a priori) and then resampled to the standard pressure grid used for the MOPITT operational radiative transfer model (Emmons et al., 2004). The entire database of NOAA aircraft profiles (http://www.esrl.noaa.gov/gmd/ ccgg/aircraft/index.html) acquired during the MOPITT mission currently includes more than $2000 \mathrm{CO}$ profiles.

\subsubsection{V6 TIR-only}

V6 TIR-only retrieval results are compared with corresponding simulated retrievals in Fig. 3 and are summarized in Table 2. Previously reported V5 TIR-only validation results (Deeter et al., 2013) are reproduced in Table 2 for comparison. At most levels, V5 and V6 TIR-only validation results are comparable, exhibiting biases of just a few percent. However, at $200 \mathrm{hPa}$, where the V5 TIR-only product exhibited a bias of $7.9 \%$, the bias has been reduced to $0.8 \%$, and the correlation coefficient $r$ has increased from 0.64 to 0.87 . A similar improvement is seen at $400 \mathrm{hPa}$. Conversely, at the surface, the retrieval bias increases slightly from 1.0 to $3.5 \%$. With respect to the total column, the bias has been reduced from $0.06 \times 10^{18}$ to $0.03 \times 10^{18} \mathrm{~mol} \mathrm{~cm}^{-2}$. 
Table 2. Summarized validation results for V5 and V6 TIR-only (V5T and V6T), NIR-only (V5N and V6N), and TIR/NIR (V5J and V6J) products based on in situ data from NOAA validation sites. Bias and standard deviation statistics for the total column are in units of $10^{18} \mathrm{~mol} \mathrm{~cm}^{-2}$. Bias and standard deviations for retrieval levels are expressed in $\%$. Total column drift is in units of $10^{18} \mathrm{~mol} \mathrm{~cm}^{-2} \mathrm{yr}^{-1}$. Drift for the retrieval levels is expressed in $\% \mathrm{yr}^{-1}$.

\begin{tabular}{|c|c|c|c|c|c|c|c|}
\hline & & Total Column & Surface & $800 \mathrm{hPa}$ & $600 \mathrm{hPa}$ & $400 \mathrm{hPa}$ & $200 \mathrm{hPa}$ \\
\hline \multirow[t]{4}{*}{ V5T } & bias & 0.06 & 1.0 & -0.1 & 0.1 & 6.0 & 7.9 \\
\hline & $\mathrm{SD}$ & 0.15 & 8.4 & 9.7 & 10 & 13 & 11 \\
\hline & $r$ & 0.94 & 0.98 & 0.94 & 0.91 & 0.82 & 0.64 \\
\hline & drift & $0.000 \pm 0.002$ & $-0.44 \pm 0.12$ & $-0.76 \pm 0.13$ & $-0.53 \pm 0.14$ & $0.59 \pm 0.19$ & $0.81 \pm 0.17$ \\
\hline \multirow[t]{4}{*}{ V6T } & bias & 0.03 & 3.5 & 1.7 & -0.0 & -0.8 & 0.8 \\
\hline & $\mathrm{SD}$ & 0.17 & 10 & 10 & 11 & 13 & 9.7 \\
\hline & $r$ & 0.93 & 0.97 & 0.92 & 0.88 & 0.81 & 0.87 \\
\hline & drift & $0.003 \pm 0.001$ & $-0.16 \pm 0.11$ & $-0.57 \pm 0.11$ & $-0.35 \pm 0.12$ & $0.70 \pm 0.14$ & $0.78 \pm 0.10$ \\
\hline \multirow[t]{4}{*}{ V5N } & bias & 0.08 & 3.1 & 3.1 & 3.5 & 3.7 & 2.3 \\
\hline & $\mathrm{SD}$ & 0.17 & 8.1 & 6.9 & 7.8 & 8.4 & 5.7 \\
\hline & $r$ & 0.91 & 0.97 & 0.89 & 0.89 & 0.89 & 0.81 \\
\hline & drift & $-0.003 \pm 0.004$ & $-0.16 \pm 0.19$ & $-0.13 \pm 0.16$ & $-0.21 \pm 0.19$ & $-0.22 \pm 0.20$ & $-0.12 \pm 0.14$ \\
\hline \multirow[t]{4}{*}{ V6N } & bias & 0.12 & 5.9 & 5.1 & 5.6 & 6.0 & 3.8 \\
\hline & $\mathrm{SD}$ & 0.18 & 9.2 & 7.3 & 8.3 & 9.0 & 6.1 \\
\hline & $r$ & 0.86 & 0.96 & 0.83 & 0.86 & 0.84 & 0.93 \\
\hline & drift & $-0.002 \pm 0.003$ & $-0.09 \pm 0.16$ & $-0.02 \pm 0.12$ & $-0.18 \pm 0.14$ & $-0.19 \pm 0.15$ & $-0.11 \pm 0.10$ \\
\hline \multirow[t]{4}{*}{ V5J } & bias & 0.08 & 2.7 & -1.1 & -4.6 & 4.0 & 14 \\
\hline & $\mathrm{SD}$ & 0.19 & 16 & 16 & 11 & 16 & 19 \\
\hline & $r$ & 0.90 & 0.92 & 0.80 & 0.84 & 0.68 & 0.48 \\
\hline & drift & $0.001 \pm 0.003$ & $-1.05 \pm 0.25$ & $-1.63 \pm 0.23$ & $-0.80 \pm 0.18$ & $1.53 \pm 0.24$ & $2.33 \pm 0.28$ \\
\hline \multirow[t]{4}{*}{ V6J } & bias & 0.09 & 8.9 & 4.2 & -2.4 & -5.2 & 3.4 \\
\hline & $\mathrm{SD}$ & 0.22 & 18 & 17 & 14 & 16 & 18 \\
\hline & $r$ & 0.89 & 0.93 & 0.82 & 0.85 & 0.74 & 0.68 \\
\hline & drift & $0.003 \pm 0.002$ & $-0.48 \pm 0.20$ & $-1.27 \pm 0.18$ & $-0.72 \pm 0.15$ & $1.08 \pm 0.18$ & $1.64 \pm 0.19$ \\
\hline
\end{tabular}

\subsubsection{V6 NIR-only}

NIR-only retrievals are mainly useful for constraining $\mathrm{CO}$ total column; these retrievals are based solely on the ratio of the Channel 6 "Difference" and "Average" signals (Deeter et al., 2009) and contain no useful information about the CO vertical distribution. Thus, the shape of MOPITT NIR-only retrieved profiles only reflects a priori information. V6 NIRonly retrieval results are compared with corresponding simulated retrievals in Fig. 4 and are summarized in Table 2. V6 NIR-only validation results indicate a positive bias at all levels ranging from about 4 to $6 \%$ which is a slight increase compared to V5 NIR-only products.

\subsubsection{V6 TIR/NIR}

V6 TIR/NIR validation results shown in Fig. 5 and summarized in Table 2 reveal biases ranging from about $-5 \%$ at $400 \mathrm{hPa}$ to $9 \%$ at the surface. Compared to the V5 product, the bias is substantially smaller at $200 \mathrm{hPa}$ (decreasing from 14 to $3.4 \%$ ) but somewhat larger at the surface (increasing from 2.7 to $8.9 \%$ ). Qualitatively, the opposing changes in the bias at $200 \mathrm{hPa}$ and the surface are consistent with the effect of changing the bias in the 7D radiance (Deeter et al., 2004) and are therefore probably the result of changing the $7 \mathrm{D}$ radiance bias correction factor. The total column retrieval bias is about $0.09 \times 10^{18} \mathrm{~mol} \mathrm{~cm}^{-2}$, which is similar to the corresponding bias for V5. VMR standard deviations range from about $10-20 \%$ and are similar to V5. The V5 and V6 TIR/NIR products exhibit relatively large random retrieval errors as the result of a strategy to increase the influence of the NIR radiances and thereby increase retrieval information content (Deeter et al., 2013). This strategy is advantageous for applications where retrieval averaging substantially reduces the effects of random error. This includes all applications of MOPITT Level 3 products, which are produced by averaging Level 2 products on a $1^{\circ}$ latitude/longitude grid. Thus, although standard deviations are larger and correlation coefficients are smaller for the TIR/NIR product compared to the TIR-only and NIR-only products, it is possible to effectively reduce random errors by sacrificing spatial resolution. 

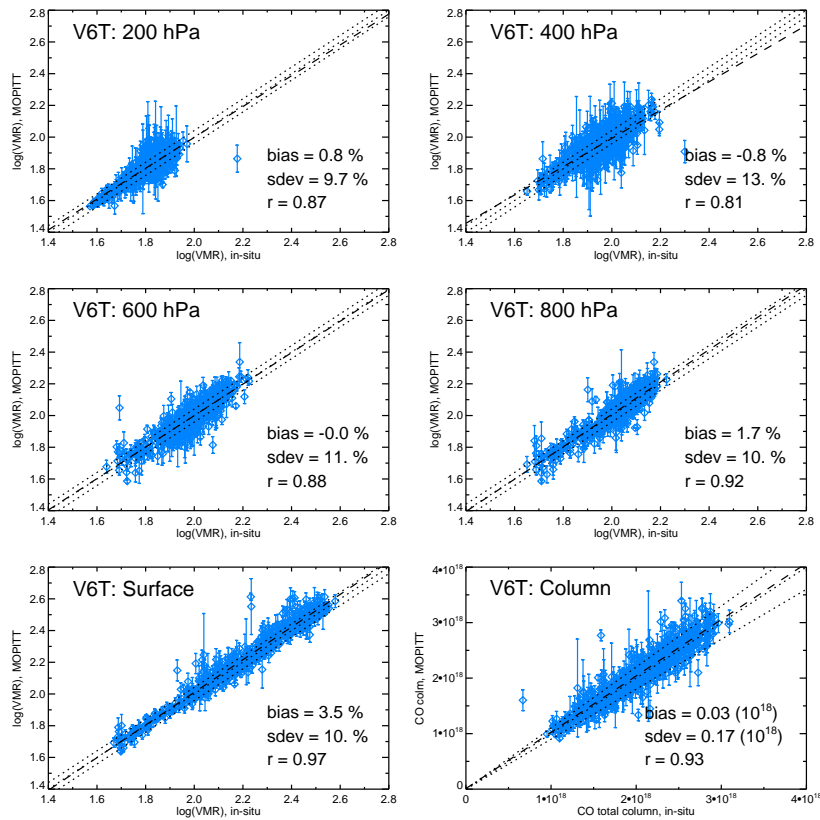

Figure 3. Scatterplots showing V6 TIR-only (V6T) validation results based on NOAA profiles. CO total column values in the bottom right panel are reported in units of $\mathrm{mol} \mathrm{cm}^{-2}$. Dotted lines in each panel indicate the ideal one-to-one dependence and $\pm 10 \%$ error boundaries. Error bars attached to each data point indicate the associated standard deviation of the retrieved $\log (\mathrm{VMR})$ values for each overpass. The dashed line in each panel shows the least-squares best fit.
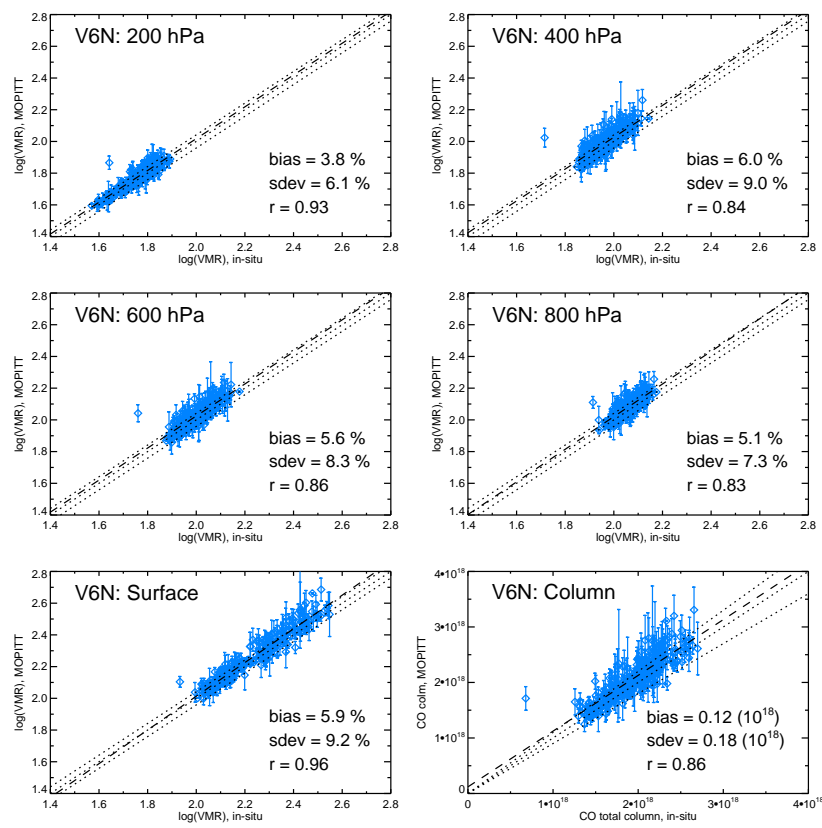

Figure 4. Scatterplots showing V6 NIR-only (V6N) validation results based on NOAA profiles. See caption to Fig. 3.
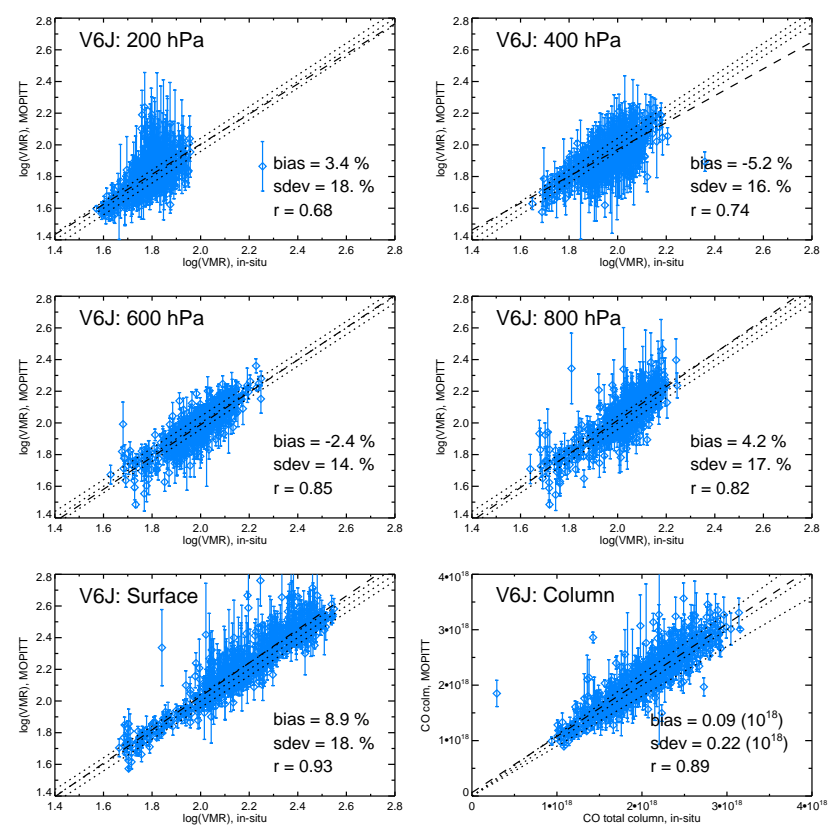

Figure 5. Scatterplots showing V6 TIR/NIR (V6J) validation results based on NOAA profiles. See caption to Fig. 3.

\subsection{Results based on HIPPO profiles}

The HIAPER Pole-to-Pole Observations (HIPPO) campaign included five phases of operations between 2009 and 2011 (Wofsy et al., 2011). A total of 567 in situ CO profiles acquired during the five phases of HIPPO were used for MOPITT validation. Each of these profiles include measurements made at a minimum pressure of $400 \mathrm{hPa}$ or less; 141 HIPPO profiles actually reached $200 \mathrm{hPa}$ or less. In addition, all profiles reached a maximum pressure of at least $800 \mathrm{hPa}$, and included measurement gaps no larger than $200 \mathrm{hPa}$. In situ profiles produced with the HIPPO measurements were extended vertically with the CAM climatology in the same manner as described in Sect. 3.1. Observations were made during January 2009 (Phase 1), October/November 2009 (Phase 2), March/April 2010 (Phase 3), June/July 2011 (Phase 4), and August/September 2011 (Phase 5). In situ measurements of atmospheric composition were performed using the QCLS (quantum-cascade laser spectrometer) instrument (Santoni et al., 2014) from approximately $67^{\circ} \mathrm{S}$ to $80^{\circ} \mathrm{N}$ mostly over the Pacific Ocean, and over a wide altitude range (from the surface up to pressures of $150-300 \mathrm{hPa}$ ). The extensive coverage of the HIPPO flights makes this data set useful for analyzing the geographical dependence of retrieval biases (Deeter et al., 2013). Since MOPITT NIR observations can only be exploited in daytime scenes over land, the HIPPO profiles are used here only to evaluate the V6 TIRonly retrieval products. 
Table 3. Summarized validation results for V5T and V6T products based on in situ data from HIPPO field campaign. See caption to Table 2.

\begin{tabular}{ccrrrrrr}
\hline & & Total column & Surface & $800 \mathrm{hPa}$ & $600 \mathrm{hPa}$ & $400 \mathrm{hPa}$ & $200 \mathrm{hPa}$ \\
\hline V5T & bias & 0.00 & 0.7 & -1.7 & -2.1 & 4.7 & 10 \\
& SD & 0.08 & 7.7 & 9.6 & 9.9 & 10 & 12 \\
& $r$ & 0.97 & 0.97 & 0.96 & 0.95 & 0.94 & 0.88 \\
\hline V6T & bias & -0.02 & 0.7 & -2.0 & -4.8 & -3.8 & 1.5 \\
& SD & 0.10 & 7.9 & 9.9 & 11 & 9.7 & 7.7 \\
& $r$ & 0.96 & 0.97 & 0.95 & 0.93 & 0.94 & 0.97 \\
\hline
\end{tabular}
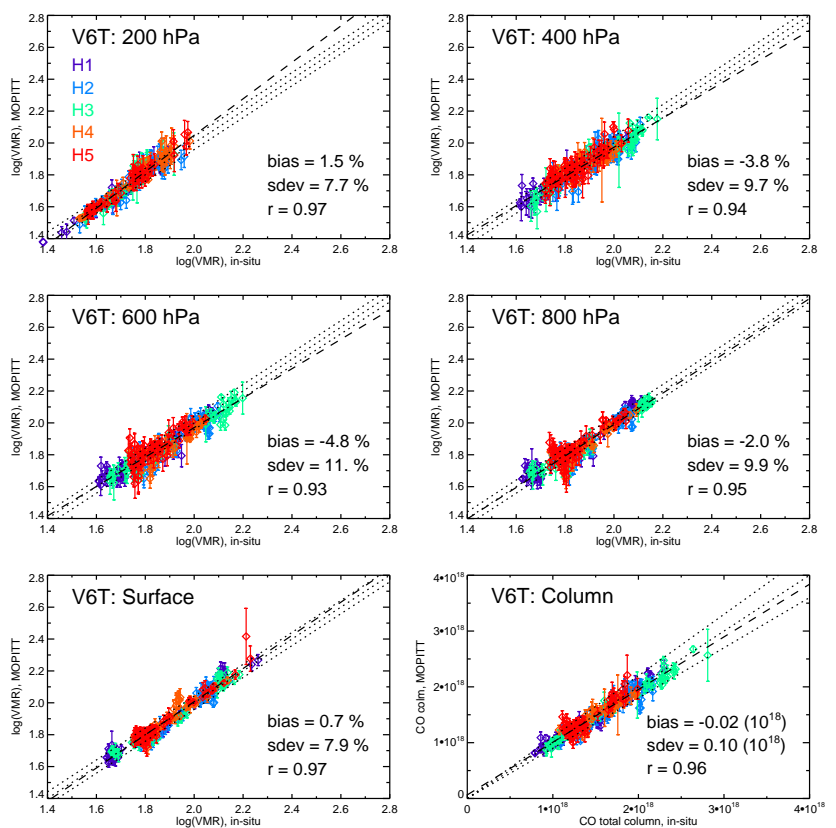

Figure 6. Scatterplots showing V6 TIR-only (V6T) validation results based on HIPPO profiles. See caption to Fig. 3. Results for each of the five phases of HIPPO are color-coded as indicated in the top left panel.

\subsubsection{V6 TIR-only}

Figure 6 presents V6 TIR-only validation results for the HIPPO profiles. Results are also summarized in Table 3. Compared to the V5 TIR-only results, a clear improvement occurs at $200 \mathrm{hPa}$, where the bias decreased from 10 to $1.5 \%$ and the correlation coefficient increased from 0.88 to 0.97 . This improvement mirrors the comparison of V5 and V6 TIR-only products based on the NOAA aircraft profiles. In other respects, V6 TIR-only validation results are similar to V5. As indicated by the standard deviation values, random retrieval errors for the HIPPO validation profiles are generally smaller than for the NOAA profiles, especially for retrieved total column. This is likely the result of both greater $\mathrm{CO}$ homogeneity within the acceptance radius for the HIPPO profiles (due to the large distances between the oceanic locations of the in situ data and continental sources)
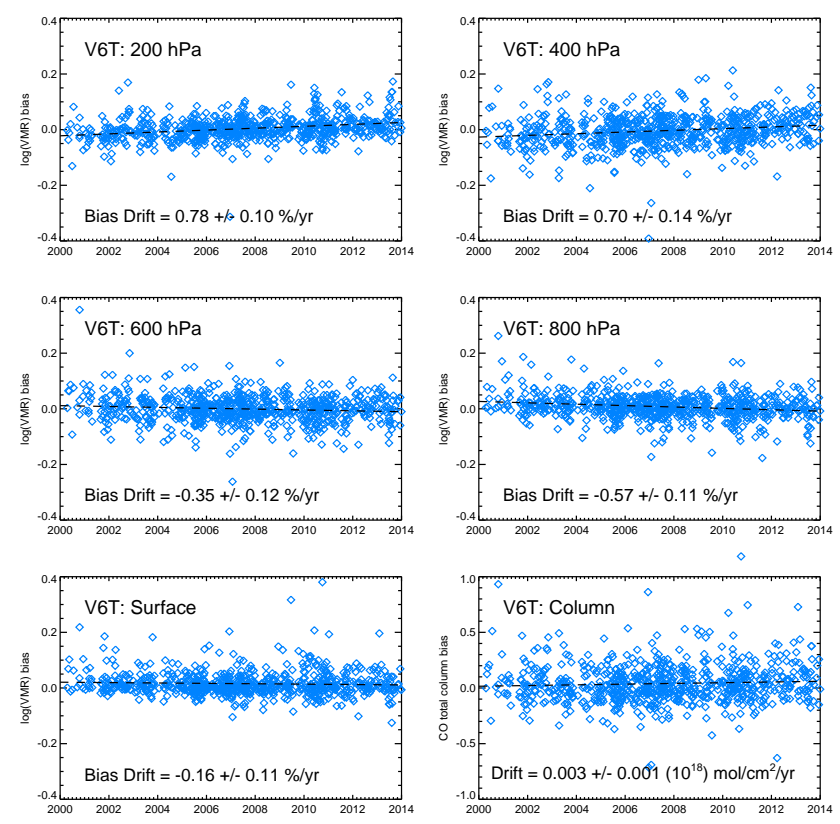

Figure 7. Time series plot showing V6 TIR-only (V6T) bias trends based on NOAA profiles.

and the statistical benefit of averaging many more individual retrievals for each overpass (due to the fourfold increase in acceptance radius).

\section{Analysis}

\subsection{Long-term stability}

The continuity and large size of the NOAA profile data set make it ideal for analyzing the long-term stability of the MOPITT products and thus justifies applications of MOPITT products involving the study of $\mathrm{CO}$ interannual variability and long-term trends (Worden et al., 2013). The time dependence of MOPITT V6 TIR-only retrieval biases (i.e., retrieved VMR values minus the corresponding in situ measurement-based values) is shown in Fig. 7. The dashed line shown in each panel is a least-squares best fit to the data. The slope of this linear fit quantifies the long-term bias drift 

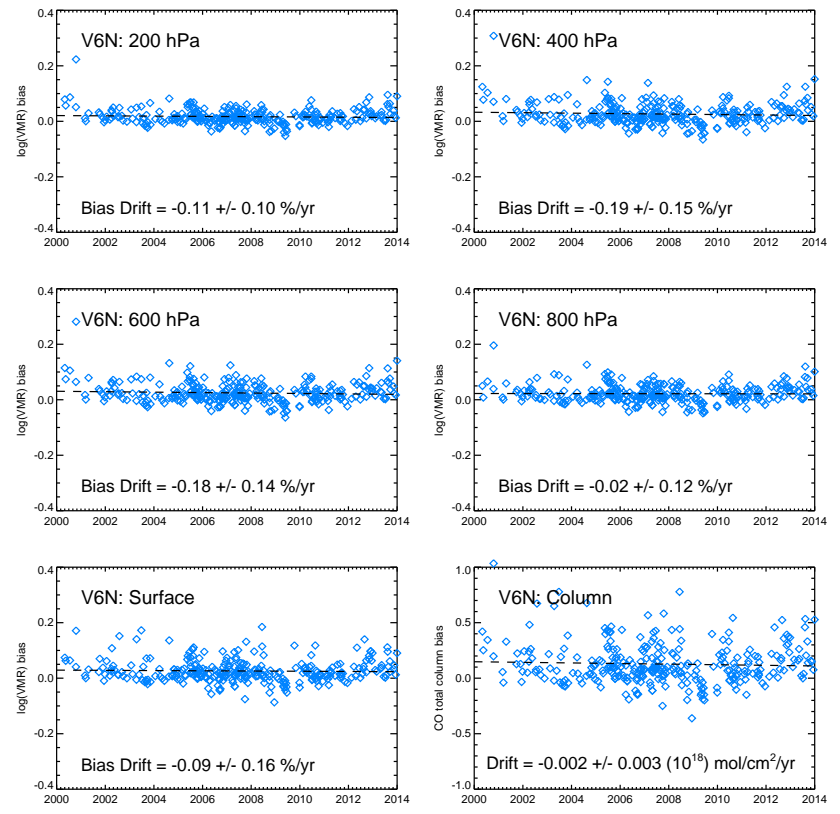

Figure 8. Time series plot showing V6 NIR-only (V6N) bias trends based on NOAA profiles.
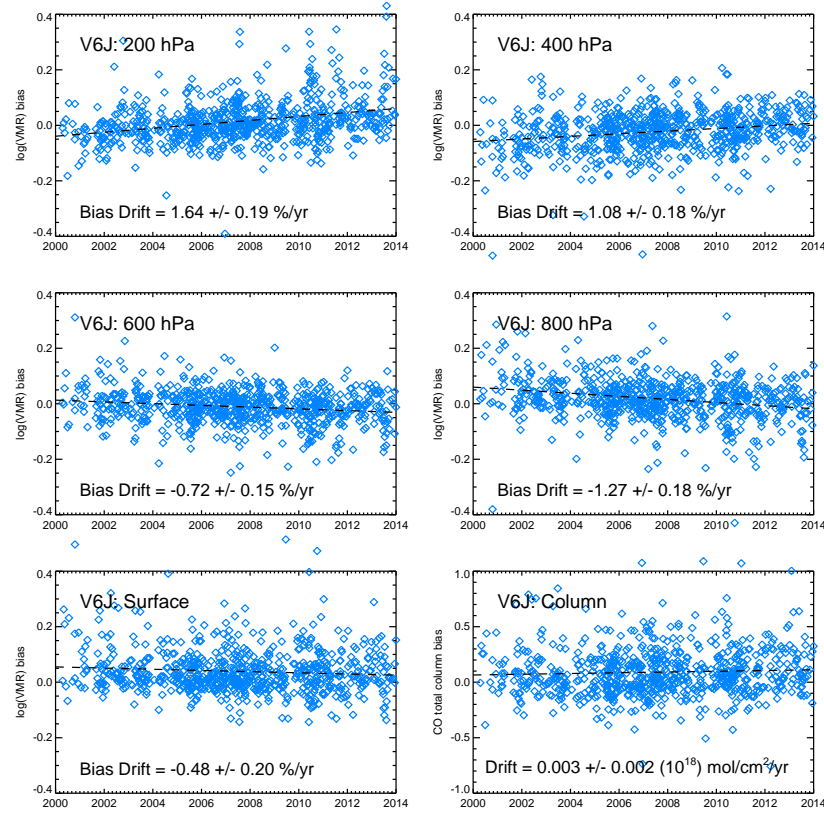

Figure 9. Time series plot showing V6 TIR/NIR (V6J) bias trends based on NOAA profiles.

and is listed in each panel and in Table 2, along with bias drift results for the V5 TIR-only product. Bias drift results for the V6 TIR-only product are mostly similar to V5 results. For both products, statistically significant positive bias drifts (i.e., bias drift values greater than the $1 \sigma$ uncertainty) are evident in the upper troposphere and opposing negative bias drifts are observed in the middle troposphere. Bias drifts are
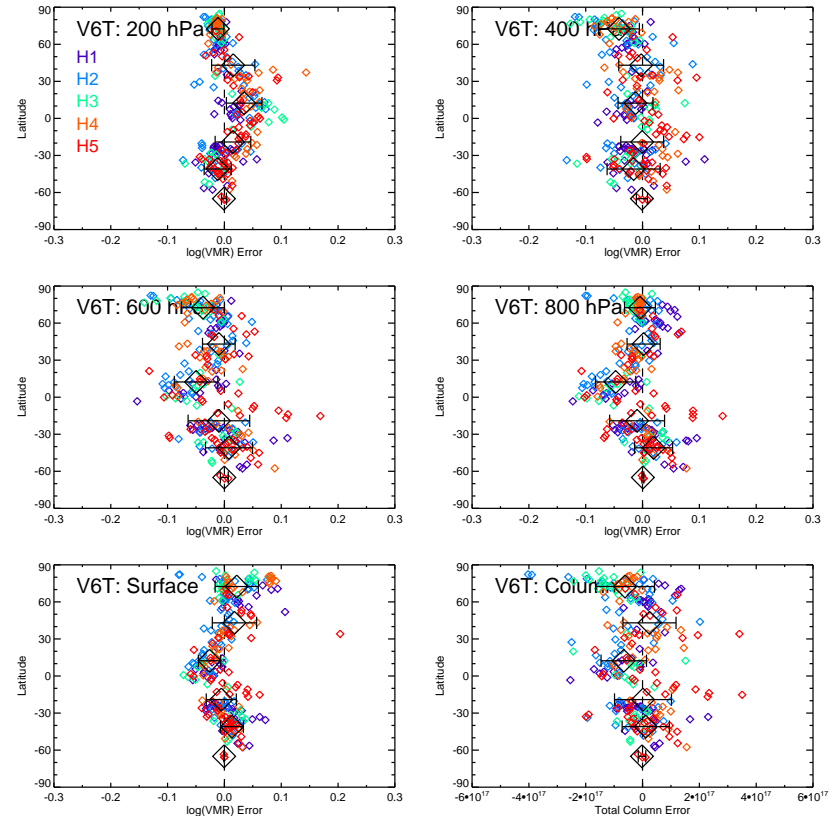

Figure 10. Latitudinal dependence of MOPITT V6 TIR-only (V6T) retrieval biases based on HIPPO profiles. Large black diamonds and error bars indicate mean biases and standard deviations within each $30^{\circ}$ wide latitudinal zone.

slightly smaller (in absolute value) for V6 compared to V5, except at the surface, where the V6 bias drift is almost negligible. Total column bias drift is nearly negligible for both the V5 and V6 TIR-only products.

Bias drift time series for the V6 NIR-only and TIR/NIR products are shown in Figs. 8 and 9 and summarized in Table 2 . For the V6 NIR-only product, the bias drift is less than $0.2 \% \mathrm{yr}^{-1}$ at all levels; this is similar to the bias drift for the V5 NIR-only product. Bias drift for the V6 TIR/NIR product varies from $-1.3 \% \mathrm{yr}^{-1}$ at $800 \mathrm{hPa}$ to $1.6 \% \mathrm{yr}^{-1}$ at $200 \mathrm{hPa}$. Compared to the V5 TIR/NIR product, the bias drift is improved at 200 and $400 \mathrm{hPa}$ but is otherwise similar. Total column bias drift for both the V5 and V6 TIR/NIR products is nearly negligible.

Since bias drift is significant in both the lower and upper troposphere, analyses of long-term CO trends at these levels should explicitly account for bias drift. Bias drift evident in V5 and V6 products could be the result of some type of instrumental degradation, changing biases in the meteorological data (NCEP and MERRA), both, or neither. Since bias drift has only been analyzed using the NOAA profile set, it is unknown whether the bias drift varies geographically.

\subsection{Geographical variability}

With wide latitudinal coverage, the HIPPO data set allows the analysis of the geographical dependence of the retrieval bias (Deeter et al., 2013). MOPITT V6 TIR-only retrieval 
biases (retrieved values minus simulated values) calculated with the HIPPO in situ profiles are plotted versus latitude in Fig. 10. The large black diamonds and error bars in each panel indicate bias statistics (mean and standard deviation) calculated over each $30^{\circ}$ wide latitudinal zone. As noted above, V5 TIR-only validation results exhibited a strong latitude dependence in the retrieval bias at $200 \mathrm{hPa}$, with biases of about $25 \%$ in the tropics. In contrast, the maximum retrieval bias in $\log (\mathrm{VMR})$ at $200 \mathrm{hPa}$ in the $\mathrm{V} 6$ results is less than 0.04 , which is equivalent to about $10 \%$. V6 results for other retrieval levels are similar to V5 results, with $\log (\mathrm{VMR})$ biases at all levels and all latitudes generally less than 0.05 . Possible causes of the latitude dependence of the retrieval bias have not been investigated.

\section{Conclusions}

The new features incorporated into the MOPITT V6 product will be relevant to some but likely not all users of MOPITT products. The improved geolocation data will clearly benefit analyses of $\mathrm{CO}$ variability on fine spatial scales, including studies of urban pollution. The reduced retrieval bias in the upper troposphere should aid studies of trace gas variability in the UTLS (upper troposphere/lower stratosphere) region. The use of a new CO climatology based on CAM-chem simulations for 2000-2009 should result in better background CO concentrations, especially near source regions. Finally, V6 retrieval processing exploits MERRA reanalysis as the source of meteorological data, offering improved spatial resolution for atmospheric variables and a more physically appropriate source for surface skin temperature.

Acknowledgements. Matthieu Pommier, at the Air Quality Research Division of Environment Canada (and now at the Pierre Simon Laplace Institute), was instrumental in helping to identify and correct the geolocation bias. The NCAR MOPITT project is supported by the National Aeronautics and Space Administration (NASA) Earth Observing System (EOS) Program. The National Center for Atmospheric Research (NCAR) is sponsored by the National Science Foundation.

Edited by: J.-L. Attie

\section{References}

Deeter, M. N.: MOPITT Geolocation Bias Analysis and Corrections, National Center for Atmospheric Research, Boulder, Colorado, United States, available at: http://web3.acd.ucar.edu/ mopitt/GeolocationBiasReport.pdf (last access: 7 June 2012), 2012.

Deeter, M. N., Emmons, L. K., Francis, G. L., Edwards, D. P., Gille, J. C., Warner, J. X., Khattatov, B., Ziskin, D., Lamarque, J.-F., Ho, S.-P., Yudin, V., Attie, J.-L., Packman, D., Chen, J., Mao, D., Drummond, J. R., Novelli, P., and Sachse, G.: Evaluation of operational radiances for the Measurements of Pollution in the Tro- posphere (MOPITT) instrument CO thermal band channels, J. Geophys. Res., 109, D03308, doi:10.1029/2003JD003970, 2004.

Deeter, M. N., Edwards, D. P., and Gille, J. C.: Retrievals of carbon monoxide profiles from MOPITT observations using lognormal a priori statistics, J. Geophys. Res., 112, D11311, doi:10.1029/2006JD007999, 2007.

Deeter, M. N., Edwards, D. P., Gille, J. C., and Drummond, J. C.: CO retrievals based on MOPITT near-infrared observations, J. Geophys. Res., 114, D04303, doi:10.1029/2008JD010872, 2009.

Deeter,M. N., Edwards, D. P., Gille, J. C., Emmons, L. K., Francis, G., Ho, S.-P., Mao, D., Masters, D., Worden, H., Drummond, J. R., and Novelli, P. C.: The MOPITT version 4 CO product: Algorithm enhancements, validation, and long-term stability, J. Geophys. Res., 115, D07306, doi:10.1029/2009JD013005, 2010.

Deeter, M. N., Martínez-Alonso, S., Edwards, D. P., Emmons, L. K., Gille, J. C., Worden, H. M., Pittman, J. V., Daube, B. C., and Wofsy, S. C.: Validation of MOPITT Version 5 thermalinfrared, near-infrared, and multispectral carbon monoxide profile retrievals for 2000-2011, J. Geophys. Res., 118, 6710-6725, doi:10.1002/jgrd.50272, 2013.

James R. Drummond, J. Zou, F. Nichitiu, J. Kar, R. Deschambaut, and J. Hackett,: A review of 9-year performance and operation of the MOPITT instrument, Adv. Space Res., 45, 760-774, doi:10.1016/j.asr.2009.11.019, 2010.

Emmons,L. K., Deeter, M. N., Gille, J. C., Edwards, D. P., Attié, J.-L., Warner, J., Ziskin, D., Francis, G., Khattatov, B., Yudin, V., Lamarque, J.-F., Ho, S.-P., Mao, D., Chen, J. S., Drummond, J., Novelli, P., Sachse, G., Coffey, M. T., Hannigan, J. W., Gerbig, C., Kawakami, S., Kondo, Y., Takegawa, N., Schlager, H., Baehr, J., and Ziereis, H.: Validation of Measurements of Pollution in the Troposphere (MOPITT) CO retrievals with aircraft in situ profiles, J. Geophys. Res., 109, D03309, doi:10.1029/2003JD004101, 2004.

Emmons, L. K., Edwards, D. P., Deeter, M. N., Gille, J. C., Campos, T., Nédélec, P., Novelli, P., and Sachse, G.: Measurements of Pollution In The Troposphere (MOPITT) validation through 2006, Atmos. Chem. Phys., 9, 1795-1803, doi:10.5194/acp-91795-2009, 2009.

Emmons, L. K., Walters, S., Hess, P. G., Lamarque, J.-F., Pfister, G. G., Fillmore, D., Granier, C., Guenther, A., Kinnison, D., Laepple, T., Orlando, J., Tie, X., Tyndall, G., Wiedinmyer, C., Baughcum, S. L., and Kloster, S.: Description and evaluation of the Model for Ozone and Related chemical Tracers, version 4 (MOZART-4), Geosci. Model Dev., 3, 43-67, doi:10.5194/gmd3-43-2010, 2010.

Lamarque, J.-F., Emmons, L. K., Hess, P. G., Kinnison, D. E., Tilmes, S., Vitt, F., Heald, C. L., Holland, E. A., Lauritzen, P. H., Neu, J., Orlando, J. J., Rasch, P. J., and Tyndall, G. K.: CAM-chem: description and evaluation of interactive atmospheric chemistry in the Community Earth System Model, Geosci. Model Dev., 5, 369-411, doi:10.5194/gmd-5-369-2012, 2012.

Pan, L., Gille, J., Edwards, D. P., Bailey, P. L., and Rodgers, C. D.: Retrieval of tropospheric carbon monoxide for the MOPITT instrument, J. Geophys. Res., 103, 32277-32290, 1998.

Rienecker, M. M., Suarez, M. J., Gelaro, R., Todling, R., Bacmeister, J., Liu, E., Bosilovich, M. G., Schubert, S. D., Takacs, L., Kim, G.-K., Bloom, S., Chen, J., Collins, D., Conaty, A., da Silva, A., Gu, W., Joiner, J., Koster, R. D., Lucchesi, R., Molod, 
A., Owens, T., Pawson, S., Pegion, P., Redder, C. R., Reichle, R., Robertson, F. R., Ruddick, A. G., Sienkiewicz, M., and Woollen, J.: MERRA: NASA's Modern-Era Retrospective Analysis for Research and Applications, J. Climate, 24, 3624-3648, doi:10.1175/JCLI-D-11-00015.1, 2011.

Rodgers, C. D.: Inverse Methods for Atmospheric Sounding, Theory and Practice, World Scientific, Singapore, 2000.

Santoni, G. W., Daube, B. C., Kort, E. A., Jiménez, R., Park, S., Pittman, J. V., Gottlieb, E., Xiang, B., Zahniser, M. S., Nelson, D. D., McManus, J. B., Peischl, J., Ryerson, T. B., Holloway, J. S., Andrews, A. E., Sweeney, C., Hall, B., Hintsa, E. J., Moore, F. L., Elkins, J. W., Hurst, D. F., Stephens, B. B., Bent, J., and Wofsy, S. C.: Evaluation of the airborne quantum cascade laser spectrometer (QCLS) measurements of the carbon and greenhouse gas suite $-\mathrm{CO}_{2}, \mathrm{CH}_{4}, \mathrm{~N}_{2} \mathrm{O}$, and $\mathrm{CO}$ - during the CalNex and HIPPO campaigns, Atmos. Meas. Tech., 7, 1509-1526, doi:10.5194/amt-7-1509-2014, 2014.

Shindell,D. T., Faluvegi, G., Stevenson, D. S., Krol, M. C., Emmons, L. K., Lamarque, J.-F., Pétron, G., Dentener, F. J., Ellingsen, K., Schultz, M. G., Wild, O., Amann, M., Atherton, C. S., Bergmann, D. J., Bey, I., Butler, T., Cofala, J., Collins, W. J., Derwent, R. G., Doherty, R. M., Drevet, J., Eskes, H. J., Fiore, A. M., Gauss, M., Hauglustaine, D. A., Horowitz, L. W., Isaksen, I. S. A., Lawrence, M. G., Montanaro, V., Müller, J.-F., Pitari, G., Prather, M. J., Pyle, J. A., Rast, S., Rodriguez, J. M., Sanderson, M. G., Savage, N. H., Strahan, S. E., Sudo, K., Szopa, S., Unger, N., van Noije, T. P. C., and Zeng, G.: Multimodel simulations of carbon monoxide: Comparison with observations and projected near-future changes, J. Geophys. Res., 111, D19306, doi:10.1029/2006JD007100, 2006.
Wofsy, S. C. and the HIPPO Science Team and Cooperating Modellers and Satellite Teams: HIAPER Pole-to-Pole Observations (HIPPO): fine-grained, global-scale measurements of climatically important atmospheric gases and aerosols, Philos. T. Roy. Soc. A, 369, 2073-2086, doi:10.1098/rsta.2010.0313, 2011.

Worden, H. M., Deeter, M. N., Frankenberg, C., George, M., Nichitiu, F., Worden, J., Aben, I., Bowman, K. W., Clerbaux, C., Coheur, P. F., de Laat, A. T. J., Detweiler, R., Drummond, J. R., Edwards, D. P., Gille, J. C., Hurtmans, D., Luo, M., MartínezAlonso, S., Massie, S., Pfister, G., and Warner, J. X.: Decadal record of satellite carbon monoxide observations, Atmos. Chem. Phys., 13, 837-850, doi:10.5194/acp-13-837-2013, 2013.

Worden, H. M., Deeter, M. N., Edwards, D. P., Gille, J., Drummond, J., Emmons, L. K., Francis, G., and Martínez-Alonso, S.: 13 years of MOPITT operations: lessons from MOPITT retrieval algorithm development, Ann. Geophys., 56, doi:10.4401/ag-6330, 2014. 